\title{
Challenges of family practice: shopping for electronics
}

$\mathrm{F}$ or many family physicians being pressed to adopt electronic medical records (EMRs), the instinct is to probably run and hide.

They don't necessarily see the merits or value of moving health records online and when they do decide to take the electronic plunge, they soon find themselves mired in sales pitches and issues of cost, connectivity and software certification.

There's no question it can be "a colossal headache," says Dr. Heath Alsaffar, who along with spouse Ann Alsaffar, president of the Canadian Family Practice Nurses Association, began introducing electronic medical records into their Ottawa, Ontario family practice office three months ago.

What lessons have they learned?

Expect hard sales pitches from vendors and a lot of unexpected problems, says Ann Alsaffar.

"The vendor does a great sales pitch," she says, adding that the equipment that vendors flog is often unnecessary. For example, one vendor tried to sell them a sophisticated photocopying machine that had the capability of producing 3000 photocopies per day. But the office doesn't need to photocopy more than 1000 items in a year.

Alsaffar adds that fortunately, her husband is tech-savvy, so he was able to "whittle this huge bill of $\$ 35000$ down to maybe $\$ 9000$." But many physicians probably don't have that savvy or the time to research their actual needs, she adds. "It's just astronomical what they (vendors) think they can sell" to doctors.

Other problems include glitches in the software itself, such as duplicate patient billing and mistyped prescriptions that can't be deleted from the system, Alsaffar says.

Expect to spend a considerable amount of time phoning and emailing the vendor's technology support teams, she adds. A review of Alsaffar's email correspondence with a vendor is enlightening. "I have not been to bed before 2 am for three nights in a row with this system trying to catch up," she once wrote to the vendor. "and we have doctors' letters and insurance letters piling up waiting due to the time taken to work on this and the time taken by on-phone training and typing emails like this. I really feel that doctors, nurses and office staff should be told up front what is in store for them before signing up for any of this."

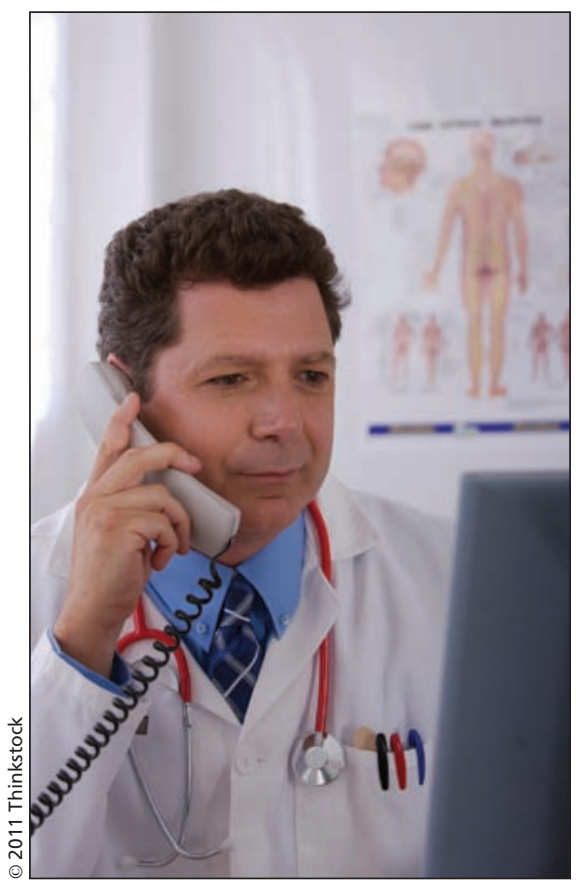

Doctors who invest in new software will likely run into glitches and should expect to spend a considerable amount of time phoning and emailing their vendors' technology support teams.

Alsaffar says that while the technology support staff was supportive, the nature of the training and services provided to clients wasn't always up to high standards. System trainers were flown in from Newfoundland and Labrador to assess the office and help with the initial setup. But the password codes to get into the system weren't properly established, so two days of socalled training were essentially wasted.

"I think there's a big disconnect between the vendors and the doctors on the ground," Alsaffar says. "It's like anything that's a change. Of course it's difficult and it's hard to change, but it's just that I think that what worries a lot of people around the country getting into this is that there needs to be an awful lot more groundwork put in.'

Yet, the problems are not always affiliated with the vendors, says Alan Brookstone, CEO of CanadianEMR, a resource organization that provides a forum for ratings and reviews of EMR systems. While a vendor needs to have sound processes in place to deal with implementation and training, the family practice itself, must be ready to join the electronic era.

Prior to implementation, a family practice should map out how EMRs will change their work flow, and designate someone in the office for advance training and as the "go-to expert" when problems arise, Brookstone says. But he concedes that "the training is not standardized and it's not as comprehensive as it could be and I think some vendors do a good job of it and other vendors don't.'

EMRs need to be more attuned to daily practice needs and vendors need to develop systems that are more useful to physicians, says Dr. Robert Boulay, president of the College of Family Physicians of Canada.

"I think physicians have certain thought pathways that we follow as we're approaching patients and I think the best EMRs are ones that we call intuitive, that kind of mimic our thought processes and bring us through steps that would reflect the normal thoughts that we're tending to go through as we're approaching a diagnosis, or approaching an office visit, approaching a patient problem," Boulay says.

Others say most available software hasn't exactly been designed for physician use.

"I do believe there's a lot of bad software out there which probably in some ways hinders people from buying it, but that's where physicians need to drive the interface so that at least it's designed with the user in mind," says Dr. Hendrik Visser, a family physician 
on Prince Edward Island, who designed his own custom software in the 1980s.

Nor do administrators typically consult physicians when purchasing EMRs for hospitals and other facilities, Visser adds. "People that are in the know and have experience front-line aren't always asked to input when it comes to vendor selection and that just doesn't make sense to me. If you haven't used, you don't know what to look for."

Others say governments have exacerbated the problem by failing to introduce suitable procedures for certifying software.

Certification authorities don't test the software, so it doesn't always meet clinical requirements, says Dr. Karim Keshavjee, CEO of InfoClin, an EMR consulting organization.

A system can pass certification to do chronic disease management without being able to do so in a practical setting, he says. For example, when Keshavjee tried to help a practice use its certified EMR to create a list of diabetic patients whose hemoglobin levels were greater than eight, the software didn't produce the right list. "Certification should mean something," he says.
"It shouldn't be a technical definition. It should be a clinical one."

Brookstone says that in developing EMRs, vendors often seek to meet provincial certification requirements, so as to qualify for development funding, rather than clinical needs. "Under the current structure, every time a province releases an update to their specifications, there's a significant cost that gets loaded onto the vendor in order to meet that specification."

Brookstone believes what's needed is an "outcome focused" national certification program, complete with some form of requirement to demonstrate that "meaningful use" can be made of the software.

Other problematic EMR areas that need to be addressed include the transfer of health information between systems, as well as the transfer of prescription information between doctor's offices and pharmacies, Brookstone adds. Improving those areas would increase the value of EMRs in Canada "two hundred fold."

EMRs that have limited clinical value put into question the billions of dollars spent by Canada Health Infoway to establish a national health infrastructure, Brookstone says. "So much money has been invested in creating this infrastructure, [but] if you can't get clinicians to use it, then what is the point of the investment?"

Some manner of national certification program, though, may soon be in the offing. Canada Health Infoway recently indicated that it will begin certifying EMR systems, based on privacy, security and interoperability criteria (www.infoway-inforoute.ca/about-info way/news/news-releases/743).

"Physicians have told us they want a simpler approach to selecting an EMR system for their practices, one that they can trust to maintain the privacy and security of information and allows them to share patient information with authorized health professionals in various health care settings," said Richard Alvarez, president and CEO of Canada Health Infoway in the press release. "Certification of EMR systems will signal to users that the product they are considering is a trusted solution that conforms to Canadian and international standards." Erin Walkinshaw, Ottawa, Ont.

\section{Challenges of family practice: using electronic records}

$\mathrm{T}$ he office is rewired. The holes have been patched where the electricians gouged out the drywall and all is freshly repainted. Patients' health records are glittering on the new laptop and all the fancy but pricey toys are humming away doing things that no one in the office completely understands but the salesman insisted were absolutely integral to the smooth operation of the electronic medical records (EMRs) system.

Now what?

Well, for most doctors, it turns out that the path to becoming a thoroughly modern electronic physician has a few more twists and turns. In fact, there are even some obstacles on the road.

Foremost among those may be the training of staff to operate the fancy new systems and the impact that initial adoption of EMRs has on the volume of family practice.
A lot of training must be provided to staff to use EMRs effectively, says Ann Alsaffar, president of the Canadian Family Practice Nurses Association, who along with husband Dr. Heath Alsaffar recently introduced EMRs into the couple's Ottawa, Ontario-based practice (www.cmaj.ca/lookup/doi/10.1503/cmaj .109-3929).

Contrary to common belief, the Alsaffars soon discovered that EMRs don't necessarily yield immediate office efficiencies because the challenges, and the time required, to implement an electronic system actually mean that less time is available to see patients.

Needless to say, that has a detrimental impact on financial bottom lines, notes Dr. Robert Boulay, president of the College of Family Physicians of Canada (CFPC).

While the upfront costs of introducing EMRs can be manageable, many physicians are unaware that doing so can result in a decrease in the number of patients seen for a period of time up to 12 to 18 months, Boulay says. "I think that's the real crux of the implementation issue. So what the CFPC really has been trying to advocate for is for increased support for physicians while they're making that transition," including financial support to hire additional required staff.

Still another obstacle lies in the tricky distinction between EMRs and electronic health records (EHRs). The former refers to recordkeeping systems at the doctor-patient level that are used primarily as an aid in the clinical diagnosis and treatment of disease. The latter refer to national electronic architecture that is used to aggregate health information in such a way that it would be valuable for policy-makers, researchers and health administrators. 